Revista de la red interuniversitaria de estudios sobre las literaturas rioplatenses contemporáneas en Francia

\title{
"Una abstracción argéntea": las traducciones de Saer de poesía norteamericana
}

\author{
Daniel Balderston
}

\section{OpenEdition} Journals

Edición electrónica

URL: http://journals.openedition.org/lirico/194

DOI: 10.4000/lirico.194

ISSN: 2262-8339

Editor

Réseau interuniversitaire d'étude des littératures contemporaines du Río de la Plata

Edición impresa

Fecha de publicación: 1 diciembre 2011

Paginación: 115-127

ISBN: 2-9525448-5-9

ISSN: 2263-2158

Referencia electrónica

Daniel Balderston, «"Una abstracción argéntea": las traducciones de Saer de poesía norteamericana », Cuadernos LIRICO [En línea], 6 | 2011, Puesto en línea el 01 julio 2012, consultado el 01 mayo 2019. URL : http://journals.openedition.org/lirico/194 ; DOI : 10.4000/lirico.194

\section{c) (i) (9)}

Cuadernos LIRICO está distribuido bajo una Licencia Creative Commons Atribución-NoComercialSinDerivar 4.0 Internacional. 


\title{
"UNA ABSTRACCIÓN ARGÉNTEA": LAS TRADUCCIONES DE SAER DE POESÍA NORTEAMERICANA
}

\author{
DANIEL BALDERSTON \\ University of Pittsburgh
}

para mi querido Hernán

$\mathrm{E}$ 1 cuaderno $56^{1}$ del Archivo Saer consta casi totalmente en traducciones poéticas del inglés. Los primeros seis poemas son traducciones de poetas clásicos chinos, retraducidos de una antología en lengua ingesa, Poems of the Late T'ang de A. C. Graham (a quien se cita a veces en las anotaciones). ${ }^{2}$ Luego sigue una versión de "The Polar Bear" de William Carlos Williams, versiones de Ezra Pound

\footnotetext{
${ }^{1}$ Ese número es provisorio por el momento: es el que ha usado el equipo de investigadores dirigido por Julio Premat en su enumeración de los cuadernos. Agradezco a Laurence Gueguen el permiso de acceder a este material, y a Julio Premat y su equipo por su ayuda, que ha sido inmensa, en este trabajo. Posteriormente a la escritura de este artículo, pude ver otros materiales que ha descubierto Laurence Gueguen (un soneto de Shakespeare, por ejemplo) en los márgenes de algunos libros de Saer. Y, en un viaje a Princeton en marzo de 2011, pude consultar los archivos de Saer que recientemente se habían clasificado en su nuevo hogar. En las carpetas de poesía hay muchas otras traducciones (de Wordsworth, Dickinson, Yeats, Dylan Thomas y Eliot entre otros). Hay también la siguiente nota, que parece ser el prólogo a las traducciones de Dylan Thomas: "Entresacados de los borradores de Dylan Thomas, estos poemas no deben ser considerados como traducciones, sino más bien como versiones personales, casi como variaciones. En último caso, podemos inferir que todo poema no es más que una versión -en el sentido en que usamos a veces esta palabra, el de un relato, entre muchos otros, de un acontecimiento, casi siempre el menos verídico. Los poemas de Thomas han desempeñado el papel que en relación con otros poemas de este mismo libro me pueden haber tenido un paisaje, un individuo, o un recuerdo. Si me abstengo de llamarlos traducciones, es sencillamente por modestia. Propongo al lector que, si le parecen buenas versiones, atribuyen el mérito a Dylan Thomas y no a mí; si le parecen malas, le queda siempre el derecho de ponerlos a mi cuenta" (Juan José Saer Papers, Princeton University Library, Box 11, Folder 8). Este artículo se limita a las traducciones del cuaderno 56, porque todavía no he podido hacer un rastreo completo de los otros materiales.
}

${ }^{2}$ Esta antología de poesía china clásica salió por Penguin en 1977. 
("Francesca" y "De Aegypto," y un par de las famosas y polémicas traducciones de Pound del chino), Walt Whitman ("City of Orgies"), D. H. Lawrence ("A Doe at Evening," "Leda" y "The Mosquito"), Wallace Stevens, Robinson Jeffers ("New Year's Dawn 1947") y Allen Ginsberg (Kaddish 44, el poema sobre Vachel Lindsay), todos ellos norteamericanos con la excepción de Lawrence. ${ }^{3}$ Williams y Stevens son los más frecuentados, con seis poemas de Williams ${ }^{4}$ y nueve de Stevens ${ }^{5}$ (algunos en más de una versión). Aquí voy a analizar algunas de estas traducciones poéticas, todas aparentemente inéditas, para elucidar las estrategias de Saer como traductor, notando su preferencia por la poesía de lengua inglesa a la hora de emprender sus traducciones (no hay traducciones de poesía francesa, a pesar de que el francés fuera idioma de su vida cotidiana y el inglés no). Según contaba el escritor, sus traducciones eran ejercicios que él hacía -para sí mismo- cuando estaba preparándose para escribir algo; en ese sentido el análisis de su labor de traductor puede arrojar nuevas e insospechadas luces sobre su producción narrativa. ${ }^{6}$

Quisiera comenzar con una traducción que parece temprana, en una hoja suelta pegada al cuaderno. Es "The House Was Quiet and the World Was Calm" de Stevens. El original dice:

The house was quiet and the world was calm.

The reader became the book; ${ }^{7}$ and summer night

\footnotetext{
${ }^{3}$ Hay también un poema persa del médico medieval Rhazes [Muhammad ibn Zakariya al-Razi], pero está copiado en inglés, de la traducción de G. S. A. Ranking: "This feeble form decaying day by day/ Warns me that I must shortly pass away./ Alas! I know not whither wends the soul When it deserts this worn and wasted clay." Saer no lo traduce al castellano sino que transcribe la traducción de Angela y Francisco Giral.

${ }^{4}$ Además de "The Polar Bear", son: "Sonnet in Search of an Author", "A Sort of Song”, "The Poem", "The Horse" y "The Last Words of My English Grandmother".

${ }^{5}$ Son: "The Indigo Glass in the Grass", "Of Mere Being", "Reality is an Activity of the Most August Imagination", "The House was Quiet and the World was Calm", "Like Decorations in a Nigger Cemetery", "Metaphors of a Magnifico", parte de "Notes on a Supreme Fiction" y "The Irish Cliffs of Moher". También copia en el inglés original el texto de "Anecdote of Men by the Thousand" pero no lo traduce.

${ }^{6}$ La mayor parte de las traducciones carecen de fechas, sin embargo, así que no me es posible sugerir relaciones específicas entre ellas y obras de Saer. Lo de las traducciones como ejercicio de calentamiento en la escritura está en la entrevista de Premat, Vecchio y Villanueva con Saer el 4 de marzo de 2005. Ver el volumen de Archivos, Glosal El entenado, Poitiers: Archivos/ Córdoba: Alción, 2010, p. 925.
}

${ }^{7}$ Esta frase se cita en el material genético de Glosa: ver Archivos, pp. 71 y 430-31. Al final de este trabajo especularemos sobre esa relación. 
Was like the conscious being of the book.

The house was quiet and the world was calm.

The words were spoken as if there was no book, Except that the reader leaned above the page,

Wanted to lean, wanted much most to be The scholar to whom his book is true, to whom

The summer night is like a perfection of thought.

The house was quiet because it had to be.

The quiet was part of the meaning, part of the mind:

The access of perfection to the page.

And the world was calm. The truth in a calm world,

In which there is no other meaning, itself

Is calm, itself is summer and night, itself

Is the reader leaning late and reading there. ${ }^{8}$

Los problemas que presentan este poema al traductor son múltiples: la repetición de ciertos vocablos ("quiet", "perfection", "itself" son apenas tres ejemplos) con delicadas variaciones de sentido o de matiz (para no hablar del verbo "was"), el contraste entre la sencillez de algunas construcciones sintácticas (las iniciales, por ejemplo) con la extrema dificultad de otras (las estrofas cuatro y ocho son notablemente difíciles), la mezcla (frecuente en la poesía de Stevens) entre una materialidad de la experiencia y de la reflexión abstracta. Hay hasta una construcción algo agramatical, "wanted much most to be", que se neutraliza en las versiones del poema en la red pero que se respeta en las ediciones críticas: Saer resuelve así los problemas:

\section{LA CASA ESTABA TRANQUILA Y EL MUNDO EN CALMA}

La casa estaba tranquila y el mundo en calma.

El lector se transformó en el libro, y la noche de verano

fue como el ser consciente del libro.

La casa estaba tranquila y el mundo en calma.

Las palabras fueron dichas como si no hubiera habido libro a no ser por el lector inclinado sobre la página,

Buscando inclinarse, buscando ser todavía más

El estudioso para quien el lector es verdadero, ${ }^{9}$ para quien

\footnotetext{
${ }^{8}$ Wallace Stevens, Collected Poetry \& Prose, comp. Frank Kermode y Joan Richardson, Nueva York: The Library of America, 1984, pp. 311-12.

${ }^{9}$ Aquí es ambigua la construcción en inglés, porque el "his" puede ser el autor o el lector. Saer ha decidido que se refiere al lector, y así pide que el autor piense en su lector como verdadero, no que el lector piense en el autor como verdadero. Agradezco a Leah Leone
} 
La noche de verano es como una perfección del pensamiento.

La casa estaba tranquila porque así tenía que ser.

La quietud formaba parte del sentido y parte de la mente:

El acceso de la perfección a la página.

$\mathrm{Y}$ el mundo en calma. Lo verdadero en un mundo en calma en el que no hay otro significado, es en sí mismo

Calma, en sí mismo verano y noche, en sí mismo

El lector inclinado y leyendo hasta tarde allí.

En el manuscrito se ven varios momentos de vacilación por parte del traductor: una palabra borrada entre "todavía" y "más" en el séptimo renglón, varias tachaduras al final del décimo (hasta dar con "así tenía que ser"), una duda entre "era parte" y "formaba parte" en el undécimo, una duda entre "en la página" y "a la página" en el duodécimo, y dos versiones del último verso: uno inicial que dice "El lector inclinado hasta tarde y leyendo allí", seguido (un tiempo después, supongo, porque está escrito en tinta de otro color) por "El lector inclinado y leyendo hasta tarde allí", con su énfasis mucho más fuerte en el adverbio final. Lo que no hay es ninguna vacilación en algunos de los puntos identificados arriba: Saer prefiere no repetir el verbo en el título del poema y en su primer verso, pone siempre "inclinado" o "inclinarse" por "lean", y mantiene "perfección" y "en sí mismo" de forma idéntica cada vez que aparecen: se porta como un traductor de filosofía a la hora de traducir vocablos esenciales al pensador. La elipsis inicial, "La casa estaba tranquila y el mundo [estaba] en calma", por ejemplo, atenúa la provocación que hace Stevens aquí: del hecho de que "la casa estaba tranquila" lleva por paralelismo la idea de que "el mundo estaba en calma", mientras "el mundo en calma" asume que esa comparación se puede hacer sin dificultades. De forma semejante, "The summer night is like a perfection of thought" no utiliza del mismo modo el concepto de "perfección" que aparece después en "The access of perfection to the page". La traducción de Saer de este poema es bellísima y atenta a las muchas sutilezas del original en inglés. Cualquier duda ante su dominio de esa lengua se disipa ante la seguridad con la que corrige "El acceso de la perfección en la página" a "El acceso de la perfección a la página": en detalles como éste se ve que atiende no sólo a los usos normales del idioma sino a las mínimas transgresiones ("access ... to").

Varias de las traducciones de William Carlos Williams vienen de su libro The Wedge, de 1944, un libro precedido por un notable manifiesto 
sobre la función del arte (que se compara a una máquina): "The arts have a complex relation to society. The poet isn't a fixed phenomenon, no more is his work" (1:53). Saer traduce el primer poema del libro, "A Sort of a Song" (1923), que contiene una de las afirmaciones más famosas de Williams:

Let the snake wait under

his weed

and the writing

be of words, slow and quick, sharp

to strike, quiet to wait,

sleepless.

-through metaphor to reconcile

the people and the stones.

Compose. (No ideas

but in things) Invent!

Saxifrage is my flower that splits the rocks. ${ }^{10}$

Es un poema famoso por el lema proclamado aquí y luego repetido mucho por Williams: "No ideas but in things" (lo repite, por ejemplo, en Paterson treinta y cinco años después). Este lema, que sirvió para definir la escuela del "imagism", aparece aquí en un poema que claramente sirve de "arte poética". La versión de Saer se llama "Una especie de canto":

Que la víbora aceche bajo

su pasto

y lo escrito

esté hecho de palabras, lento y rápido, filoso ${ }^{11}$

al golpear, calmo en la espera,

insomne.

-reconciliar, gracias a la metáfora,

la gente y las piedras.

Compone. (Las ideas,

únicamente en las cosas) iInventa!

Saxífraga es mi flor, que hiende

las rocas.

\footnotetext{
${ }^{10}$ William Carlos Williams, The Collected Poems of William Carlos Williams, Volume I: 1909-1939, comp. A. Walton Litz y Christopher MacGowan, Nueva York, New Directions, 1986, p. 55.

${ }^{11}$ Aquí de nuevo Saer modifica delicadamente el sentido. En el original, lo que es "lento, rápido y filoso" son las palabras, no "lo escrito". Es decir, el énfasis cae más en el proceso en el original y en el producto en la traducción. Agradezco nuevamente a Leah Leone.
} 
Aquí Saer no intenta hacer nada con la aliteración, tan importante en el sonido del poema en inglés, pero sí trabaja con el ritmo extraño, los versos cortos y largos, los encabalgamientos, la sintaxis fragmentada. Y claramente reconoce la importancia del poema como definición de una poética, ya que también traduce dos otros metapoemas de Williams, "Sonnet in Search of an Author" y "The Poem". Este último dice:

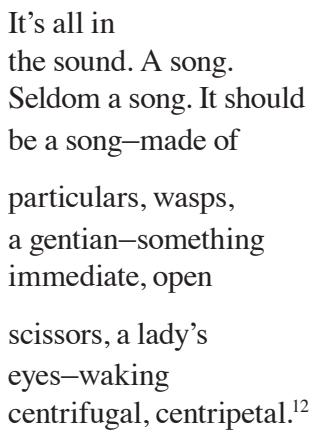

Este texto lo traduce dos veces Saer en el cuaderno: hay una primera versión en una hoja que también tiene una traducción de "The Horse" (del libro The Wedge), y otra en una hoja aparte (que parece más pulida y sin embargo aparece antes en el cuaderno). La versión más limpia dice:

Todo está en el sonido. Un canto.

Raramente un canto. Debería ser

un canto - hecho de

detalles, avispas,

una genciana - algo

inmediato, tijeras

abiertas, el ojo de

una dama - despertando

centrífugo, centrípeto.

La otra versión titubea con respecto al primer verso: propone "Está entero en" además de "Todo está en el", y pone dos veces el verbo ser, al final del tercer verso y (respetando la versión original) al principio del cuatro, entre paréntesis. En las dos versiones pone los guiones de modo equidistante entre las palabras, reconociendo que no forman paréntesis (como suelen funcionar en español) sino que acentúan las

\footnotetext{
${ }^{12}$ William Carlos Williams, The Collected Poems of William Carlos Williams, Volume II: 1939-1962, comp. Christopher MacGowan, Nueva York: New Directions, 1988, p. 74.
} 
pausas o los desvíos. Ya que este poema es otra vez una proclamación sobre la importancia de las cosas en la poesía-concretismo podríamos llamarlo, aunque no en el sentido brasileño- confirma que uno de los motivos del interés de Saer en la poesía de Williams es esa insistencia en lo material.

Un fragmento interesante en estos papeles es el inicio de "Notes Toward a Supreme Fiction", uno de los grandes poemas filosóficos de Stevens. Saer traduce apenas los primeros dos tercetos de la primera sección, "It Must Be Abstract". El original comienza:

Begin, ephebe, by perceiving the idea

Of this invention, this invented world,

The inconceivable idea of the sun.

You must become an ignorant man again

And see the sun again with an ignorant eye

And see it clearly in the idea of it. ${ }^{13}$

Saer traduce, bajo el título "Debe ser abstracta":

Comienza, efebo, por percibir la idea de esta invención, este mundo inventado, la inconcebible idea del sol.

Debes volver a ser ignorante y ver el sol otra vez con ojo ignorante $\mathrm{y}$ verlo claramente en su idea.

La totalidad de este poema (25 páginas en la edición de The Library of America) tiene que haberle interesado a Saer por su insistencia en lo abstracto ("It Must Be Abstract"), el cambio ("It Must Change") y el placer ("It Must Give Pleasure"). A la vez, como es una meditación sobre la creación del universo que expresa una falta de fe religiosa por parte de Stevens, es llamativa su selección. Aunque sólo traduce el inicio del texto, es notable otra vez su interés en poemas como éste que tienen que ver con el pensar de modo abstracto la función, y las modalidades, de la poesía.

Esta tendencia se observa en otros de los poemas traducidos: los de Ginsberg, Lawrence y Pound también se pueden considerar reflexiones sobre el quehacer poético. De Pound traduce dos poemas tempranos, "De Aegypto" y "Francesca" (dos veces), y retraduce (al español)

\footnotetext{
${ }^{13}$ Wallace Stevens, Collected Poetry \& Prose, Nueva York: The Library of America, 1984, p. 329.
} 
algunas de las traducciones de Pound de poesía china. De Lawrence traduce "The Mosquito", "Leda" y "A Doe at Evening", poemas que enfatizan otra vez la experiencia en sus aspectos concretos (son poemas epifánicos como tantos otros textos de Lawrence). Podemos dar como ejemplo el poema "Francesca" de Pound, que Saer traduce dos veces. El original dice así:

You came in out of the night

And there were flowers in your hands,

Now you will come out of a confusion of people,

Out of a turmoil of speech about you.

I who have seen you amid the primal things

Was angry when they spoke your name

In ordinary places.

I would that the cool waves might flow over my mind,

And that the world should dry as a dead leaf,

Or as a dandelion seed-pod and be swept away,

So that I might find you again,

Alone. ${ }^{14}$

Aquí la fascinante ambigüedad del poema reside en quien es el hablante (no en vano Pound lo incluye en la colección Personae, que abunda en el uso de voces ajenas): ¿es Paolo? ¿es Dante? ¿es Pound? ¿son los tres a la vez? El poema se convierte en un esfuerzo de rescate de la figura de Francesca del mundo del chisme, pero a la vez está escrito desde el conocimiento de una de las colecciones más ilustres de chismes, la Divina Commedia, donde es uno de los pasajes más famosos. De las dos versiones del poema la más pulida es:

Venías desde la noche

y había flores en tus manos;

ahora vendrás de la confusión de la turba

y del tumulto de discurso sobre tu persona.

Yo que te he visto entre las cosas primeras

me enfurecí al escuchar tu nombre

proferido en lugares comunes.

Que la ola fría fluya sobre mi mente

y que el mundo se seque como una hoja muerta

o como una cáscara de semilla, y sea barrido,

para que pueda encontrarte otra vez,

sola.

${ }^{14}$ Ezra Pound, Personae, Nueva York: New Directions, 1971, p. 36. 
En las dos versiones Saer anota el significado de "dandelion seedpod" ("vaina de achicoria", pone dos veces) sólo para resolver la dificultad de otro modo ("como una cáscara de semilla"). Otras notables decisiones son el uso de "sobre tu persona" en el cuarto verso (en las dos versiones) en vez del más directo "about you" del original, y el uso del imperativo ("Que la ola fría fluya") en vez del potencial usado en el original para expresar preferencias ("I would that the cool waves might flow"). "Ordinary places" no tendría que traducirse como "lugares comunes", pero el matiz metafórico de esta expresión funciona bien en el poema. "Sobre tu persona" hace pensar de nuevo en la cuestión de las máscara poéticas, tan importante en la poesía de Pound (recordemos otra vez que Pound tituló su colección de poemas cortos Personae). Hay una tendencia en esta traducción hacia el desdibujamiento del yo, tan importante en el poema a la vez que tan ambiguo, y sin embargo cuando el español le da ocasiones de borrar casi del todo al yo, por lo menos de forma explícita, como en el verso "I who have seen you amid the primal things", Saer resuelve mantenerlo, con énfasis: "Yo que te he visto entre las cosas primeras". El poema mantiene su extraña relación con el episodio de la Commedia de Dante: el hablante poético es a la vez alguien que conoce directamente a Francesca y alguien que sólo la conoce a través del poema, donde está contaminada por "la confusión de la turba" y el "tumulto de discurso". La quiere tener a solas, y sola, pero eso queda como un deseo imposible.

Para terminar quisiera comentar otra traducción brillante de un poema notable, de la que quedan dos versiones. El poema de Wallace Stevens "Reality is an Activity of the Most August Imagination" es una reflexión a partir de un viaje en auto por Connecticut:

Last Friday, in the big light of last Friday night,

We drove home from Cornwall to Hartford, late.

It was not a night blown at a glassworks in Vienna

Or Venice, motionless, gathering time and dust.

There was a crush of strength in a grinding going round,

Under the front of the westward evening star,

The vigor of glory, a glittering in the veins,

As things emerged and moved and were dissolved,

Either in distance, change or nothingness,

The visible transformations of summer night,

An argentine abstraction approaching form

And suddenly denying itself away. 
There was an insolid billowing of the solid.

Night's moonlight lake was neither water nor air. ${ }^{15}$

Aquí una de las muchas dificultades es la traducción de "argentine abstraction", ya que claramente se refiere no al país (y eso que ahora estamos en bicentenario del 25 de mayo) sino a un matiz plateado. Saer resuelve el poema así, bajo el título "La realidad es una actividad de la más augusta imaginación"

El último viernes, en la gran luz de la noche del último viernes,

Volvíamos en auto a casa desde Cornwall hacia Hartford, tarde.

No era un soplo nocturno en una cristalería en Viena

O Venecia, inmóvil, amontonando tiempo y polvo.

Era una molienda de fuerza en pulverización giratoria ${ }^{16}$

Bajo la faz de la estrella del poniente,

El vigor de la gloria, un brillo en las venas

Como si las cosas emergieran, se movieran y se disolvieran

En la distancia, en el cambio o en la nada,

Las transformaciones visibles de la noche de verano,

Una abstracción argéntea insinuándose en una forma

y descartándose a sí misma (un) ${ }^{17}$ poco después.

Era una agitación no sólida de lo sólido.

El lago de luz lunar de la noche no estaba hecho ni de agua ni de aire.

Es interesante aquí como Saer traduce "approaching" por "insinuándose" y "denying itself" por "descartándose a sí mismo": la búsqueda poética es activa, dueña de sí. También es notable cómo el español obliga a ampliar mucho la sintaxis, ya en el título pero de modo fuerte en "Either in distance, change or nothingness" y en el último verso, donde ocho palabras en el original se transforman en diecisiete en la traducción. Claro que las traducciones del inglés al español suelen ampliarse en extensión por las diferencias sintácticas entre las dos lenguas, pero estos son casos excepcionales de ese fenómeno. También

\footnotetext{
${ }^{15}$ Wallace Stevens, Collected Poetry \& Prose, Nueva York: The Library of America, 1984, pp. 471-72.

${ }^{16}$ Este es un ejemplo notable de la conciencia de Saer de los diferentes recursos de las dos lenguas: el original con su fuerte aliteración y sus verbos convertidos en sustantivos ( "a grinding going round"), la traducción con su vocabulario latinizante ( "pulverización giratoria").

${ }^{17}$ Escribió “un” y después le puso paréntesis, pero sin tacharlo. A mí me parece mejor sin el artículo.
} 
es notable la musicalidad del final del poema en la traducción, gracias al largo aliento del verso y a la aliteración.

Saer escoge poemas difíciles: emprender una traducción de "Reality is an Activity of the Most August Imagination" es una prueba de su lectura a fondo de cierta poesía moderna en lengua inglesa, de su manejo de las sutilezas de esa lengua, y de su capacidad de buscar en el nuevo texto "la más augusta imaginación". Es sensible a los matices del lenguaje, la precisión del vocabulario, el sonido, la sintaxis. Sus traducciones varían mucho entre sí, como esfuerzos divergentes de encontrar maneras de sentir la voz de poetas que son, a la vez, muy diferentes. A la vez, hay una constante en la voz poética del traductor: una búsqueda de imágenes concretas que a la vez son motivos de una reflexión abstracta. "Una abstracción argéntea": María Moliner aclara que el adjetivo se puede usar de forma figurada para referirse al "[b]rillo de las obras de arte o de la inteligencia". Nuestro argentino argénteo ejerce aquí, una vez más, pero de forma absolutamente secreta, el brillo de su arte y de su inteligencia.

Al principio de este trabajo me preguntaba sobre la relación entre estas traducciones, proyecto privado, y la obra édita del autor. Es una pregunta difícil de contestar en general, ${ }^{18}$ por el hecho de que la mayoría de las traducciones no están fechadas y se encuentran en un cuaderno aparte, sin visible contacto con los cuadernos de trabajo de las otras obras. Hay una excepción, que nos permite especular sobre la relación: el segundo verso de "The House Was Quiet and the World Was Calm" aparece citado en inglés en los materiales genéticos de Glosa. En la edicion de Archivos, el documento de "Las siete cuadras siguientes" dice que hay una nota marginal, "and the reader became the book", al lado de la frase siguiente del manuscrito, que corresponde a la tercera página de la segunda sección de la novela:

Y su relato, segun lo que queda del relato de Botón en el del Matemático, es más o menos así: una noche tranquila del último verano; son pasadas las doce. Después de una cena liviana; Washington, con una jarra de agua fría y un plato de ciruelas, se ha instalado en su estudio para leer, tomando notas de cuando en cuando, una edición facsimilar de la Relación del abandonado, del padre Quesada; que Marcos Rosemberg le ha traído de Madrid. ${ }^{19}$

\footnotetext{
${ }^{18}$ Otro ejemplo que no voy a discutir aquí, por tratar de una traducción de prosa, es la de The Picture of Dorian Gray que intenta el juez en Cicatrices.

${ }^{19}$ Juan José Saer, Glosal El entenado, Poitiers: Archivos, 2010, p. 71.
} 
Allí está la anotación del verso de Stevens. Después sigue el pasaje:

Poco a poco, el hervor del día se ha mitigado, y el ronroneo interno que atraviesa, monótono, con su tren de apariciones, la parte iluminada de la mente, se ha ido entrecortando, gracias a la punta clara de su atención que, como el filo de un diamante, ha venido abriéndose paso para relegar, con ajustes sucesivos, los pliegues de lo oscuro. A partir de cierto momento, después de varios intentos trabajosos, los pliegues se retiran y las caras del diamante, emergiendo de la oscuridad, se concentran en la punta transparente que se estabiliza y se fija, para después alcanzar la perfección al desaparecer a su vez, de modo tal que no únicamente el ronroneo, que es tiempo, carne y barbarie, sino también el libro y el lector desaparecen con ella, despejando un lugar en el que lo intemporal y lo inmaterial, no menos reales que la putrefacción y las horas, victoriosos, se despliegan. ${ }^{20}(71-72)$

Es decir, en un nudo complejo de la novela Glosa, que entrelaza la escritura de ese proyecto con el proyecto anterior, El entenado, Saer evoca el poema de Stevens con su reflexión sobre la lectura. Washington se convierte en el libro que lee, que es el libro que leímos poco antes. En ese libro, el poema de Stevens sirve para definir espacios de reflexión y escritura: el claustro donde el naufrago cuenta su historia al padre Quesada, quien le enseña a leer y a escribir, y el lugar donde años después escribe sus memorias, que incluyen en abismo la serie de narraciones anteriores, a Quesada y a los espectadores de la obra teatral. El poema sirve entonces para marcar la relación entre experiencia, representación, lectura y experiencia, una vuelta completa. El poema forma parte de esa relación circular, y de hecho define como real, y como abstracción hecha real en la página, el esfuerzo del lector. Aquí tenemos entonces, por un momento evanescente pero eterno, a Saer, meditando a través de un poema que ha traducido, o que está por traducir, que lo ayuda a definir su relación con su obra. No importa que la traducción sea secreta: el poema de Stevens deja su huella sutil en el pasaje, en el pliegue y el despliegue del texto: "abstracción" "libro", "lector" adquieren connotaciones específicas gracias a ese intertexto secreto. Saer lector está "inclinado y leyendo hasta tarde allí": ha hecho suyo el poema, y le sirve para avanzar en su escritura.

${ }^{20}$ Juan José Saer, Glosa/ El entenado, Poitiers: Archivos, 2010, pp. 71-72, 


\section{Bibliografía}

Graham, Angus Charles, Poems of the Late T'ang. Harmondsworth, Penguin Classics, 1977.

Pound, Ezra, Personae, Nueva York, New Directions, 1971.

SAER, Juan José, Cuaderno 56: traducciones poéticas. Manuscrito inédito. , Glosa/ El entenado. Edición crítica dirigida por Julio Premat, Poitiers, Colección Archivos/ Córdoba, Alción, 2010.

, Juan José Saer Papers. Rare Books and Manuscripts.

Princeton University Library. C1393.

Stevens, Wallace. Collected Poetry \& Prose. Comp. Frank Kermode y Joan Richardson, Nueva York, The Library of America, 1984.

Williams, William Carlos. The Collected Poems of William Carlos Williams, Volume I: 1909-1939. Comp. A. Walton Litz y Christopher MacGowan. Nueva York, New Directions, 1986.

,The Collected Poems of William Carlos Williams, Volume II: 1939-1962. Comp. Christopher MacGowan. Nueva York, New Directions, 1988. 